
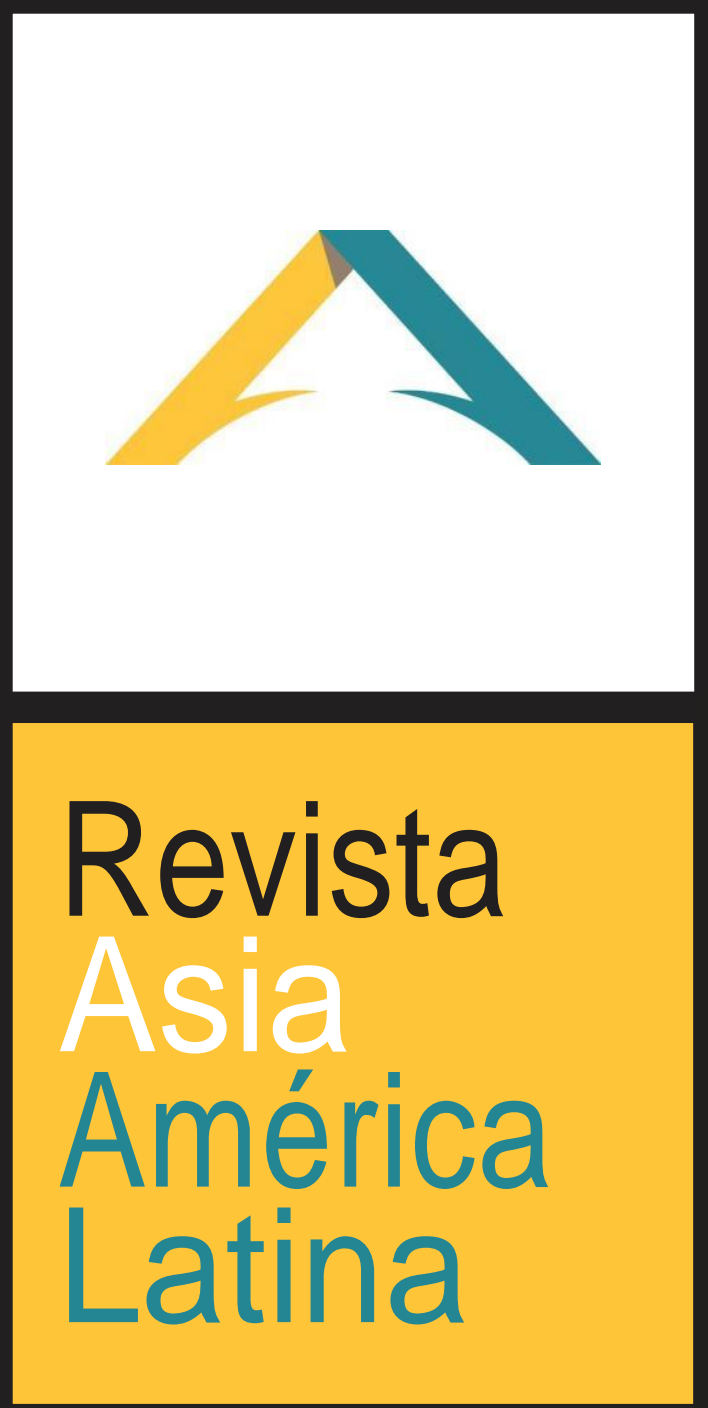

ISSN 2524-9347

Grupo de Estudios sobre Asia y América Latina Instituto de Estudios de América Latina y el Caribe Universidad de Buenos Aires

EU

DE BA 
Destinos heredados: discursos de pérdida territorial en Estados poscoloniales a través del Pacífico (Perú y las Filipinas, 1903-1927)

JORGE BAYONA

Inherited Destinies: Discourses of Territorial Loss in Postcolonial States across the Pacific (Peru and the Philippines, 1903-1927).

Jorge Bayona, Verge: Studies in Global Asias, Volumen 3, Número 2, 2017, pp. 169-94. (Artículo). Editado por Tina Chen y publicado por la University of Minnesota Press (Minneapolis, Minn.).

\section{DESTINOS HEREDADOS: DISCURSOS DE PÉRDIDA TERRITORIAL EN ESTADOS POSCOLONIALES A TRAVÉS DEL PACÍFICO (PERÚ Y LAS FILIPINAS, 1903-1927) ${ }^{1}$}

\section{Jorge Bayona}

Universidad de Washington

jbayona@uw.edu

\section{Introducción}

Entre 1903 y 1927, las élites en Lima y Manila se movilizaron en torno a la defensa de su amenazada integridad territorial. La creación de una administración militar estadounidense separada para las poblaciones musulmanas y lumad (no cristianas) en el archipiélago de Sulu y en el centro y sur de Mindanao fue seguida por conversaciones sobre la separación permanente de estos territorios de las Filipinas, e incluso sobre la anexión completa por parte del recientemente llegado poder colonial (Gowing, 1977; Abinales, 2000). Más o menos en el mismo período, las élites peruanas en Lima también expresaban sus preocupaciones por la posibilidad de la desposesión territorial, en su caso, de los vastos territorios de selva a lo largo de las orillas del río Putumayo, que podrían cometer secesión o acabar en manos de la vecina República de Colombia (Basadre, 1961). La enorme distancia geográfica que separa a Perú de las Filipinas, así como la diferencia en el estatus político entre una república independiente y lo que era aún una posesión colonial, podrían verse como condiciones que impiden un estudio comparativo fructífero entre ambos. No obstante, en este artículo propongo analizar estos procesos dentro de un marco discursivo que puede trascender estas distancias: el del «destino heredado».

\footnotetext{
${ }^{1}$ Me gustaría agradecer a Vicente Rafael, Adam Warren, Laurie Sears y Christoph Giebel por sus orientación y retroalimentación tan valiosas en la hechura de este artículo. Asimismo, me gustaría agradecer a Florencia Figar y Max Povse por su traducción al español.
} 
Destinos heredados: discursos de pérdida territorial en Estados poscoloniales a través del Pacífico (Perú y las Filipinas, 1903-1927)

JORGE BAYONA

Hay precedentes históricos y académicos significativos para la comparación entre Perú y las Filipinas. Por supuesto, ambos comparten la experiencia histórica de la colonización hispánica, con sus regiones «centrales» o «metropolitanas» habiendo sido conquistadas en el siglo XVI, durante la fase de expansión más agresiva y evangelizadora de España; mientras que los consiguientes intentos de someter a los territorios que se encontraban fuera de estas regiones ocurrieron mucho más tarde, entre los siglos XVII y XIX, cuando las reglas de la conquista habían sufrido transformaciones significativas. Los paralelos posibles son tales que Benedict Anderson (2016) comentó que si no fuera por el surgimiento del concepto del Sudeste asiático como una región en sí misma, las Filipinas podrían haber sido estudiadas como una parte de América Latina. Otros ejemplos de cómo estas dos regiones pueden ser vistas dentro de un marco común incluyen el estudio de John D. Blanco (2004) sobre las trayectorias del filipino José Rizal y del cubano José Martí con relación a sus críticas del colonialismo español, y la inclusión por Doris Sommer (1999) de un artículo del académico filipinista Vicente Rafael en su libro The Place of History: Regionalism Revisited in Latin America. Una imagen reversa de ello es la inserción de Benedict Anderson (1998) de un capítulo sobre Perú en su libro The Spectre of Comparisons, que está dedicado mayormente al Sudeste asiático. En sus elocuentes palabras: «bajo cierta luz, [las Filipinas] parecen haber flotado hacia el Oeste distante desde el litoral de los Andes hispánicos» (p. 20).

Aun así, a pesar de la sugerencia de Anderson de mirar a las Filipinas como una extensión de los Andes, ya había diferencias significativas entre estas áreas hacia el comienzo del siglo XX. En primer lugar, durante varios siglos sus roles e importancia dentro del Imperio Español difirieron significativamente: mientras Perú era un gran virreinato que contribuía con significativas cantidades de plata al Imperio, las Filipinas eran un apéndice del virreinato de Nueva España que era usado mayormente como un intermediario para el comercio con China. Políticamente, sus destinos divergieron luego de que las posesiones españolas en la América continental ganaran su independencia en la década de 1820; por su parte, las Filipinas permanecieron como una parte del Imperio Español archipelágico hasta la década de 1890, cuando finalmente declaró la independencia en medio de una serie de guerras que involucraron no solo a España, sino también a los Estados Unidos. Esto configura la diferencia principal entre estos casos: para el comienzo del siglo XX, Perú era una república completamente independiente que estaba acercándose a su centenario, mientras que las Filipinas habían tenido solo una breve experiencia republicana antes de que fuera aplastada por los Estados Unidos en la guerra filipino-estadounidense entre 1899-1902. En el período que abarca este artículo, las Filipinas permanecieron siendo una posesión colonial, aunque con un nuevo amo. 
Destinos heredados: discursos de pérdida territorial en Estados poscoloniales a través del Pacífico (Perú y las Filipinas, 1903-1927)

JORGE BAYONA

Sin embargo, un trabajo comparativo productivo puede ser hecho, no a pesar de estas diferencias, sino debido a ellas. Como Florencia Mallon (1995) señaló al estudiar las interacciones campesinas con nociones de nacionalismo y el Estado en México y Perú, los estudios comparados raramente encuentran casos perfectamente simétricos, en tanto generalmente tienen formas y rasgos diferentes, pero este «desequilibrio, en vez de ser un defecto, ofrece una entrada a la riqueza y productividad analíticas» (pp. 221-222). Es precisamente este desequilibrio lo que quiero aprovechar para realizar una comparación productiva.

Las diferencias entre Perú y las Filipinas nos permiten estimar cuán útil sería hablar de una retórica de destino heredado como una justificación para una serie de prácticas territoriales llevadas adelante por dos Estados antes controlados por el Imperio Español. Su estudio en un solo caso -o aun en más de un caso dentro de la misma región — sufriría el riesgo de descubrir un patrón que solo sería válido dentro de dicha región.

¿Qué es, después de todo, la retórica del «destino heredado», y cómo los casos de Perú y las Filipinas nos permiten verlo en acción? Siendo un obvio juego de palabras con la expresión «destino manifiesto», la locución «destino heredado» se refiere a dos aspectos de la retórica usada por las élites de Perú y las Filipinas para presentar sus reclamos territoriales. Estos han sido «heredados», porque el derecho sobre estos territorios disputados por los Estados que estas élites decían representar era derivado de los reclamos expuestos por sus predecesores coloniales, de esta manera convirtiendo a las regiones fronterizas coloniales en su herencia. $\mathrm{Y}$ son un «destino», porque a pesar de la ausencia de un control efectivo sobre el territorio y de una comunalidad cultural con los pueblos de esas áreas, las élites gobernantes sentían que era su «destino» histórico asimilar estas tierras y sus habitantes a sus metrópolis. De este modo, el destino heredado es un tipo de discurso que justifica y esconde la expansión de Estados-nación nominalmente no imperiales en los remanentes territoriales del imperio.

A pesar de su claro objetivo, la naturaleza de la retórica del destino heredado revela dos contradicciones inherentes. Los territorios reclamados por las élites en las capitales _Lima y Manila_ acabaron por existir en dos estados opuestos y contradictorios: eran simultáneamente «ya poseídos» y aún «no conquistados». De este modo, pueden argüir que otras naciones o Estados vulneran su «integridad territorial», y al mismo tiempo proponen vastos proyectos de exploración del territorio que era todavía básicamente desconocido para ellos, así como proyectos de colonización por parte de ciudadanos convencionales que se impondrían a los habitantes indígenas de estas regiones. Estos pueblos indígenas también existían en dos estados contradictorios. Podían ser «filipinos» o «peruanos» y simultáneamente rechazados como tales. Los proyectos de construcción nacional rechazaban el «salvajismo» de los pueblos no convencionales al negarles su ciudadanía, o incluso su humanidad básica, mientras que simultáneamente pretendían ser sus administradores y protectores legítimos ante «otros» amenazantes que quisieran tratar de tomar su tierra. 
Destinos heredados: discursos de pérdida territorial en Estados poscoloniales a través del Pacífico (Perú y las Filipinas, 1903-1927)

JORGE BAYONA

Estas contradicciones en la retórica del destino heredado producen resultados fructíferos cuando las introducimos en discusiones académicas más amplias sobre la naturaleza de los regímenes de poder siguiendo la tríada foucaultiana de soberanía, disciplina y gubernamentalidad. Foucault sugiere que primero vemos las sociedades de soberanía, que ejercen el poder sobre el territorio a través de la ley; luego el surgimiento de las sociedades de disciplina, que ejercen el poder sobre los individuos a través de la vigilancia; finalmente, lassociedades de gubernamentalidad, que ejercen el poder a través de los aparatos de seguridad. Foucault (2007) clarifica, sin embargo, que no es el caso en el que un régimen de poder hace obsoleto al anterior, sino más bien es la superposición de una multiplicidad de mecanismos. En el caso de Perú y las Filipinas, podemos ver cómo, mientras sus élites gobernantes estaban imbuidas en el marco de la gubernamentalidad — esto es, cuidaban a sus poblaciones como un medio para lograr mayor prosperidad- en sus áreas centrales y metropolitanas, a través de medidas tales como las campañas contra las epidemias o en favor de la educación (Cueto 2001; Hollnsteiner y Ick 2001), las contradicciones en su retórica concerniente a estas áreas en disputa revelan una lógica subyacente de soberanía. El uso de argumentos legalistas para defender sus derechos territoriales sobre lo que eran en realidad tierras indígenas, en vez de preocupaciones verdaderas y sostenidas sobre las condiciones de vida de sus habitantes — que eran difícilmente considerados conciudadanos- muestra cómo la soberanía toma precedencia sobre la gubernamentalidad.

No obstante, en las páginas que siguen, también intentaré tomar en cuenta las críticas de Dipesh Chakrabarty (2000) sobre la comprensión histórica de la modernidad, por la que las sociedades poscoloniales son entendidas a menudo como «quedándose atrás» de desarrollos históricos que solo pueden ser teorizados en base a Europa. De este modo, en vez de presentar la retórica del destino heredado y sus contradicciones como un artefacto de la occidentalización fallida o como un paso que traería al histórico «todavía no» más cerca de su fruición, trataré de analizarla como un discurso de élite particular que parte de su propia metrópolis, como resultado de sus propias necesidades históricas más que como un eco de desarrollos en otro lugar. En este sentido, mientras la tríada foucaultiana soberanía-disciplina-seguridad es una lente útil para enmarcar este discurso, no busco convertirla en simplemente una confirmación empírica de teorías eurogénicas del ejercicio del poder, sino más bien entenderla como un fenómeno por derecho propio. Por lo tanto, este ensayo no solo busca comprender una cierta retórica poscolonial; también busca involucrarse en la creación de conceptos desde los márgenes de la «Europa hiperreal» de Chakrabarty.

La práctica de abordaje en casos de la «periferia» como un punto de partida para una teoría más general ha probado ser un emprendimiento fructífero. Anderson (1998) ha comentado cómo sus estudios sobre el Sudeste asiático lo llevaron a escribir Comunidades Imaginadas, y Thongchai Winichakul (1994) propuso el útil concepto de «geocuerpo» —un conjunto 
Destinos heredados: discursos de pérdida territorial en Estados poscoloniales a través del Pacífico (Perú y las Filipinas, 1903-1927)

JORGE BAYONA

de valores y prácticas relacionadas con un territorio- basándose en sus estudios sobre Tailandia. El caso tailandés en particular ha producido una historiografía robusta en asuntos de territorio y soberanía que pueden servir como un punto de partida para una discusión de las prácticas y retóricas peruanas y filipinas (Strate, 2015; Loos, 2006, pp. 72-99). Mientras que los reclamos tailandeses sobre «territorios perdidos» están basados en la reinterpretación «moderna» por parte de las élites de Bangkok del significado de las relaciones tributarias entre esa ciudad y estados más pequeños en la periferia, así como de la supuesta cultura común de los pueblos tailandés, laosiano y jemer (pero no de los musulmanes en el sur) — todo lo cual fue utilizado para sostener la causa de una soberanía homogénea y absoluta-, los Estados poshispánicos como Perú y las Filipinas usualmente no siguieron el mismo camino. Sin embargo, podemos todavía observar cómo —en todos los casos - las concepciones «modernas» de espacio fueron impuestas -a menudo de manera violenta_ por Bangkok, Lima o Manila sobre pueblos nativos que no compartían las nociones de las élites de fronteras fijas y precisas, soberanía homogénea y ciudadanía bien definida, sin importar que la fuente de legitimidad fuera una entidad política precolonial o colonial.

A pesar de que Walter Mignolo (2003) ha argüido convincentemente que las concepciones indígenas de espacio y tiempo no fueron abandonadas por completo a pesar de la conquista española, en el caso de Perú y México, o de la intromisión europea, en el caso de China, los reclamos territoriales peruanos o filipinos no estaban basados usualmente en las relaciones precolombinas, hayan sido tributarias o de otro tipo. Entre las concepciones andinas de espacio que Mignolo estudió podemos observar incluso cómo el cronista indígena Guaman Poma consideraba a los habitantes nativos de la selva como «bárbaros hostiles que comen carne humana», ubicándolos fuera del mundo «civilizado» de los incas, de manera similar a como otros bárbaros estaban fuera del Reino Medio chino en sus propios mapas (pp. 252, 221). A pesar de cuánto guste a los nacionalistas peruanos evocar al Imperio Inca, sus reclamos territoriales están siempre basados en la documentación colonial (Pons Muzzo, 1962). En el caso de las Filipinas, sus intelectuales nunca recurrieron a estados preeuropeos — como Majapahit en Indonesiacomo una fuente de legitimidad territorial. Ninguno de los estados existentes abarcaba todo el archipiélago filipino, y para complicar el asunto aún más, eran musulmanes, y dos de ellos — Sulu y Maguindanao- estaban entre los territorios que querían asimilar. ${ }^{2}$ De este modo, las nociones de qué territorios constituían los geocuerpos del Perú y las Filipinas del siglo XX eran puramente la creación del amo colonial; sus ambiciones territoriales habían sido decididamente «heredadas».

${ }^{2}$ La excepción podría ser su reclamo posterior sobre Sabah, arguyendo que pertenecía al Sultanato de Sulu, y por lo tanto debería ser transferida a las Filipinas. 
Destinos heredados: discursos de pérdida territorial en Estados poscoloniales a través del Pacífico (Perú y las Filipinas, 1903-1927)

JORGE BAYONA

Este estudio exploratorio de la retórica del destino heredado está basado en el análisis de las reacciones de las élites peruanas y filipinas en relación a la potencial pérdida de dos regiones remotas específicas. En primer lugar, está la región del Putumayo, ubicada en el lejano rincón noreste de Perú, que comprende mayormente el área entre los ríos Napo y Amazonas, en el sur, y el Caquetá en el norte, con el Putumayo atravesándola por la mitad. Estando poblada por pueblos amazónicos, como los boras y los yaguas, el colonialismo misionero español y republicano fue limitado. Hacia el comienzo del siglo XX, la demanda mundial por el caucho puso una prima sobre los recursos de la región, desencadenando una competencia intensa por ella entre Colombia y Perú. En segundo lugar, la región Sulu-Mindanao incluye las regiones del archipiélago Sulu y la mayor parte de la isla de Mindanao, ambos ubicados en el sur lejano de las Filipinas. Siendo habitadas por pueblos musulmanes y lumad (aquellos que no son ni musulmanes ni cristianos), los españoles fueron incapaces de someter a estas regiones a una colonización prolongada y efectiva, sea a través de medios militares o religiosos. Aun cuando habían ocupado exitosamente los sultanatos de Sulu y Maguindanao, su control efectivo estaba limitado al área inmediata alrededor de sus guarniciones. Serían los estadounidenses a comienzos del siglo XX quienes finalmente derrotarían a los musulmanes del sur en batalla y amenazarían con separar su territorio del resto de las Filipinas.

Mi periodización está basada no solo en los procesos históricos que conciernen a las disputas territoriales y al uso de la retórica del destino heredado, sino también en criterios históricos más amplios en ambos países. Los primeros años del siglo XX representaron el fin del período de reconstrucción que siguió a la desastrosa derrota de Perú en la Guerra del Pacífico (1879-1883), y el principio del período conocido como la República Aristocrática, que estuvo caracterizada por el gobierno de las élites criollas en Lima afiliadas al Partido Civilista, con voto restringido, educación obligatoria, caciques provinciales y clientelistas en el interior, y un impulso general hacia la modernización. Aunque rompió con las élites tradicionales en 1919, la administración de Augusto Leguía, que duró once años, continuó impulsando una modernización al estilo occidental bajo un régimen autoritario y plutocrático. Para las Filipinas, 1903 ocurre inmediatamente después del fin oficial de la catastrófica Guerra FilipinoEstadounidense (1899-1902), y es el año en que fue fundada la administración militar de los Estados Unidos en la Provincia del Moro. Este período temprano en el gobierno estadounidense sobre las Filipinas estuvo caracterizado por la educación masiva (en inglés), el control local de la Asamblea filipina por élites que conformaban el Partido Nacionalista, el voto restringido, un capitalismo corrupto, clientelismo, y un impulso fuerte a la modernización y a la preparación de las Filipinas para la independencia. Como se puede ver, parece haber ciertas similitudes, a pesar de la importante diferencia de la presencia imperial estadounidense. El final de este período estuvo marcado 
Destinos heredados: discursos de pérdida territorial en Estados poscoloniales a través del Pacífico (Perú y las Filipinas, 1903-1927)

$$
\text { JORGE BAYONA }
$$

por el acuerdo sobre la cuestión del destino de los territorios en disputa en 1927 en ambos países. Y aunque Perú iría a la guerra por esas tierras en 1932, el contexto posterior a 1929 posee otros factores para tomar en consideración.

¿Cuáles son los intereses académicos en juego cuando se discute la retórica del destino heredado? Propongo que esta retórica puede ser hallada en los reclamos territoriales de muchos otros Estados poscoloniales en América Latina o el Sudeste asiático. Por ejemplo, Benedict Anderson (2006) ya ha ofrecido algunos pensamientos preliminares sobre cómo el mapeo y la noción de «geocuerpo» fueron desplegados en los reclamos de Indonesia sobre Papúa Occidental, y creo que la retórica del destino heredado podría ser un marco útil para analizar los reclamos ecuatorianos y bolivianos sobre la selva amazónica o el arriba mencionado reclamo indonesio sobre Papúa Occidental. Comprender la retórica del destino heredado como un mecanismo que oculta lo que es en verdad una expansión imperial podría cuestionar la «naturalidad» de los geocuerpos reclamados por las élites alrededor del mundo, cuyos argumentos jurídicos han sido a menudo tomados como la realidad histórica.

\section{Perú: apoyando la retórica del destino heredado con la fuerza de las armas}

Los reclamos territoriales en la selva amazónica por parte de repúblicas sudamericanas independientes fueron heredados de dos maneras. En el sentido territorial, las élites tomaron el Tratado de San Ildefonso de 1777 entre España y Portugal como la línea de base que dividía sus territorios de los del Imperio del Brasil, rechazando cualquier posibilidad de terra nullis y, por lo tanto, de cualquier soberanía que no fuera derivada de la europea. Por ejemplo, esta herencia era todavía considerada válida por el intelectual y jurista patricio peruano Francisco García-Calderón ([1907] 2001), aun admitiendo que los oficiales españoles no habían sido capaces de explorar la frontera. Y aun cuando el principio jurídico general de uti possidetis — de acuerdo al cual cada una de las nuevas repúblicas recibiría el territorio correspondiente a la jurisdicción de la administración colonial entendida como su predecesora - era considerado por los intelectuales peruanos como inferior a la «libre voluntad del pueblo» de una determinada provincia, su delimitación exacta debía ser el resultado de investigaciones exhaustivas sobre cuáles eran las fronteras de esas adscripciones territoriales durante el período colonial (García-Calderón [1907] 2001; Palma 1935; Belaunde 1942). Por muy maximalistas que hubieran sido los deseos peruanos de conformar su propio geocuerpo, siempre estuvieron necesariamente enmarcados en un reclamo justo al territorio que el acta de independencia de España le había legado a la república.

La otra cualidad heredada de estos reclamos territoriales está relacionada con las estructuras sociales coloniales. Debido a una larga historia de peruanos coloniales que veían a los habitantes de la región amazónica como diferentes e inferiores, aquellos que expresaron su deseo de pertenecer a Perú luego de la independencia, eran en realidad los herederos de las jerarquías sociales del 
Destinos heredados: discursos de pérdida territorial en Estados poscoloniales a través del Pacífico (Perú y las Filipinas, 1903-1927)

JORGE BAYONA

período colonial, no los habitantes nativos de la región. Los indios amazónicos habían sido apartados como salvajes infieles y violentos que rechazaban los generosamente ofrecidos beneficios de la religión cristiana y la civilización occidental (García Jordán 2001). Miembros de las élites sociales e intelectuales peruanas de comienzos del siglo XX continuaron estas prácticas retóricas, apartando el discurso del «destino heredado» del discurso de «pérdida territorial» descrito por Shane Strate sobre Tailandia, según el cual los intelectuales tailandeses afirmaban que «laosiano» y «jemer» eran categorías inventadas por Francia para dividir a un pueblo tailandés étnicamente homogéneo (Strate, 2015, pp. 48-54). García-Calderón ([1907] 2001, pp. 70-71) describe al hombre de la selva como «aún salvaje, no tiene siquiera la grandeza de pensamiento para vencer esta naturaleza que lo aplasta». El abogado e intelectual patricio Víctor Andrés Belaunde ([1930] 1963, pp. 22-23) distinguía a los indios «pacíficos» de las tierras altas de los indios «guerreros» de la selva; y aun el intelectual marxista José Carlos Mariátegui (1969) — cuyos escritos revelan un fuerte apego a los pueblos indígenas de los Andes- es claramente desdeñoso respecto a los pueblos del Amazonas, declarando que «Su civilización antigua no alcanzó probablemente, sino un nivel muy bajo. Sus idiomas y dialectos numerosos; en general pobres en términos abstractos, su tendencia a la destrucción numérica de la raza; también son caracteres opuestos a los de los indios Incásicos» (p. 50).

El deseo de los peruanos de cumplir el destino de Perú de finalmente consolidar su geocuerpo estaba motivado no solo por las nociones abstractas de integridad territorial, sino también por intereses materiales concretos. La selva amazónica desde hacía mucho era conceptualizada como un vasto territorio de riquezas sin explotar que llevaría a la metrópoli a la prosperidad. Las exploraciones de los siglos XIX y XX parecieron confirmarlo: la región del Putumayo se convirtió primero en una fuente de quina y luego de caucho. En la primera parte del período estudiado, el caucho era una importante fuente de ingresos para el país, lo que despertó más interés en su futuro en sus intelectuales, aunque este disminuyó en importancia hacia la década de 1920 (Stanfield 1998; García-Calderón [1907] 2001; Mariátegui [1928] 1943). ${ }^{3}$ A pesar del colapso del valor del caucho, la selva amazónica continuó siendo vista como un tesoro de riquezas desconocidas durante el resto del siglo XX.

En lo que respecta a la «conquista» de estos ricos territorios, podemos observar qué papel juegan las contradicciones inherentes a la retórica del destino heredado. García-Calderón ([1907] 2001), por ejemplo, luego de haber declarado inequívocamente que los derechos peruanos sobre estos territorios derivaban no solo de la ley y la herencia sino también de la posesión territorial fáctica, luego declara que la naturaleza de sus recursos «aún no ha sido revelada, dado que la

\footnotetext{
3 Véase West Coast Leader, 14 de diciembre de 1921; 11 de enero de 1922; Variedades, 17 de septiembre; 5 de noviembre de 1921.
} 
Destinos heredados: discursos de pérdida territorial en Estados poscoloniales a través del Pacífico (Perú y las Filipinas, 1903-1927)

JORGE BAYONA

conquista de las tierras pantanosas es dificultosa» (pp. 296, 319). De esta manera, estos territorios selváticos son simultáneamente poseídos por Perú y todavía deben ser explorados o conquistados. La contradicción concerniente a las poblaciones nativas de la selva deriva de su propia existencia, o de su inexistencia. Habiendo ya comentado sobre el atraso de los pueblos «salvajes» de la selva amazónica, García-Calderón declara en otras ocasiones que es una tierra vacía y sin poblar cuyos recursos naturales están esperando ansiosamente ser explotados por gente más avanzada (pp. 66, 209). ${ }^{4}$ En este sentido, la selva amazónica puede ser al mismo peligrosa, debido a la presencia de los «salvajes», y tentadora, debido a la ausencia de población.

Hay numerosas maneras en las que uno puede observar cómo, a pesar del lenguaje jurídico sobre la propiedad, los peruanos han sido conscientes de un clivaje dentro de «su» territorio. Militarmente, el Virreinato del Perú había tenido que establecer un anillo de fuertes para proteger las tierras altas en que se habían asentado de los indios amazónicos que los amenazaban, como aquellos que apoyaban la rebelión de Juan Santos Atahualpa de la década de 1740 (García Jordán, 2001), constituyendo de esta manera una frontera de facto mucho más al oeste de donde estaba la frontera de jure con las posesiones portuguesas. Después de la independencia, fue básicamente solo a través de la ocupación militar, como la construcción de muelles navales en Iquitos en la década de 1860, que los asentamientos peruanos en la cuenca del Amazonas pudieron tener éxito. Esta ciudad puerto se convirtió en la base de avanzada desde la cual Perú podía sostener sus reclamos territoriales en el área, y desde donde sus pobladores podían recorrer la selva en busca de caucho y gente para esclavizar (Stanfield, 1998; García Jordán, 2001). La presencia continuada de indios «no peruanos» viviendo en la selva amazónica fue reinterpretada como una prueba del control peruano: además de sus argumentos jurídicos a favor de la posesión peruana de la región, Víctor Andrés Belaunde argüía que las campañas ocasionales de represión del Perú contra los «salvajes» que atacaban los asentamientos peruanos constituían una prueba del control efectivo de su país sobre la región - a pesar de lo contradictorio que pueda parecer- (Belaunde, 1942). Cuán reciente fue la colonización peruana de la región del Putumayo disputada por Colombia —y la mentalidad con la que fue llevada a cabo- puede ser inferido por alguno de los nombres dados a los asentamientos que se encuentran en la región. Los puestos de avanzada coloniales Tarapacá, Arica y Tacna fueron todos nombrados por las provincias perdidas a Chile durante la guerra que terminó en 1883.

A pesar de los estados contradictorios en los que existían estos territorios (ya poseído-aún no conquistado), las élites peruanas consistentemente afirmaban su compromiso en mantener la totalidad del geocuerpo previsto, y que cualquier concesión sería comprendida como una pérdida de territorio sentida tan

\footnotetext{
${ }^{4}$ Véase West Coast Leader, 22 de enero de 1922.
} 
Destinos heredados: discursos de pérdida territorial en Estados poscoloniales a través del Pacífico (Perú y las Filipinas, 1903-1927)

JORGE BAYONA

profundamente como las pérdidas frente a Chile. De esta manera, GarcíaCalderón ([1907] 2001, p. 312) podía describir con nostalgia la política externa de Perú después de 1879 como habiendo «aceptado en numerosos tratados internacionales cláusulas que iban contra sus derechos, cediendo sin vacilar regiones de nuestro territorio». Es precisamente desafíos de este tipo los que enfrentarían —o creían enfrentar- durante este período.

\section{1. Disputando la región del Putumayo}

Siendo una república independiente, los únicos obstáculos que impedían que Perú impusiera militarmente su soberanía de cara a la creciente presión colombiana, eran las pesadillas logísticas y la geografía que separaba a la metrópoli de su colonia. Sin embargo, estos obstáculos no deber ser tomados a la ligera. No había caminos que conectaran la costa o las tierras altas con Iquitos, la principal base de Perú en el Amazonas, lo que significaba que viajar por tierra era tan oneroso que a menudo era más expeditivo enviar el material y el personal militar a través de los océanos Pacífico y Atlántico hacia Brasil, desde donde se navegaba río arriba hasta Iquitos. Esta falta de comunicación es ejemplificada por el hecho de que, en una fecha tan tardía como 1921, el semanario en idioma inglés West Coast Leader sugería el establecimiento de un servicio regular de navíos entre Callao e Iquitos, y en 1922, Variedades todavía pedía por la terminación de un camino por tierra que conectara la costa con Iquitos. ${ }^{5}$ Un oficial militar apostado en Iquitos comentó cómo era rutina para los oficiales y soldados peruanos que eran enviados allí, la necesidad de tomar una ruta que iba de Callao a Panamá, Nueva York, y luego río arriba por el Amazonas a través de Pará y Manaos (Torres Videla [1922], p. 78). En términos del número de días del viaje y las distancias involucradas, Iquitos parecía tan lejos como una colonia de ultramar. Si las condiciones llevaran a la guerra, sin embargo, Perú tenía la libertad de responder con cualquiera de los recursos militares que tuviera a mano, con una expectativa razonable de éxito. Y aunque Perú todavía lidiaba con las secuelas de la Guerra del Pacífico, Colombia más recientemente había tenido que lidiar con las consecuencias de la Guerra de los Mil Días que había rasgado al país. De ser necesario, ambos países intercambiarían golpe por golpe. Con las ganancias del caucho atrayendo a aventureros de ambos países, el conflicto parecía cada vez más probable, y eventualmente se desataría en 1911.

Luego de descubrir una guarnición colombiana en el banco derecho del río Caquetá, dentro del geocuerpo previsto de Perú, su gobierno recurrió al uso de la fuerza. En un combate que sería conocido como el conflicto de La Pedrera, tropas peruanas y barcos de vapor bajo el comando del Teniente Coronel Óscar Benavides incursionaron desde la ciudad costera de Chiclayo hacia Iquitos, lo

\footnotetext{
${ }^{5}$ West Coast Leader, 10 de septiembre de 1921; Variedades, 1 de abril de 1922.
} 
Destinos heredados: discursos de pérdida territorial en Estados poscoloniales a través del Pacífico (Perú y las Filipinas, 1903-1927)

JORGE BAYONA

que les proveyó con las ventajas logísticas necesarias para desalojar a las fuerzas colombianas (Basadre, 1961). ${ }^{6}$ La percepción de amenazas a sus reclamos territoriales está claramente presente en la retórica de Lima, en la que Perú es descrito como estando «rodeado de graves dificultades externas, constantemente amenazado en su integridad y en su derecho». ${ }^{7}$ De esta manera, a pesar del hecho de que la guarnición colombiana había establecido un campamento en un territorio en las orillas de un río principal, hasta entonces desconocido para cualquier peruano (fue recién durante este combate que los peruanos descubrieron una pequeña cascada a través de la cual navegaron, permitiéndoles flanquear la posición del enemigo), la retórica del destino heredado demandaba el uso de términos como «recuperación» —en vez de «conquista»— en la cobertura del evento: «La recuperación del Caquetá y zona de la excelente posición militar 'La Pedrera', donde esfuerzo tropas colombianas sucumbió el día 12 (sic) ante la bravura de nuestros soldados, importa un triunfo moral y material para el Perú, asegurando zona Putumayo». ${ }^{8}$ Esto, por supuesto, no significa que los reclamos colombianos sobre el territorio estuvieran más justificados que los de los peruanos; en su lugar, podemos observar que la retórica del destino heredado sirve para ocultar cómo estos dos Estados poscoloniales estaban tratando de tallar sus propios «imperios» territoriales en territorio indígena.

Aunque el conflicto militar en sí mismo había sido breve, desencadenó una ráfaga de justificaciones en la prensa peruana sobre la validez de sus reclamos sobre el área del Putumayo. Y aunque la retórica anticolombiana luego del incidente de La Pedrera fue notoriamente tenue en medio de las celebraciones patrioteras de la victoria militar, ${ }^{9}$ los peruanos procedieron a cuestionar las motivaciones detrás de las aspiraciones territoriales de Colombia en la selva amazónica. El Comercio, echando culpas por el conflicto sobre la invasión colombiana, enuncia que:

Colombia ha querido llevar sus soldados á donde tenían que chocar con los nuestros, $\mathrm{y}$, venciendo dificultades de todo género, porque la naturaleza la aleja de esos, para ella remotos é impenetrables parajes del oriente, envió, sistemáticamente, fuerzas á los ríos tributarios del Amazonas peruano y provocó, al fin, el conflicto. ${ }^{10}$

El énfasis puesto en los peligros enfrentados por los colombianos sugiere que su presencia allí es ilegítima, y que la región del Putumayo de hecho pertenece a

\footnotetext{
${ }^{6}$ Véase El Comercio, 4, del 7 al 10, 13 y 14 de agosto de 1911.

${ }^{7}$ El Comercio, 7 de agosto de 1911.

${ }^{8}$ El Comercio, 14 de agosto de 1911, énfasis añadido.

${ }_{9}^{9}$ Véase El Comercio, 7, 9 y 14 de agosto de 1911.

${ }^{10} \mathrm{El}$ Comercio, 23 de agosto de 1911, énfasis añadido.
} 
Destinos heredados: discursos de pérdida territorial en Estados poscoloniales a través del Pacífico (Perú y las Filipinas, 1903-1927)

JORGE BAYONA

aquellos que tienen un acceso más fácil a ella, es decir, a los peruanos. Sin embargo, los elogios constantes hacia el estoicismo de los tenaces soldados peruanos que «valientemente atravesaron los mismos obstáculos» naturales prueban la especiosidad de esta línea de pensamiento. De hecho, unas semanas después del combate, se reportó que la mayoría de los soldados peruanos que habían tomado la posición colombiana habían caído enfermos y que serían reemplazados por gente del Departamento de Loreto — del cual Iquitos es la ciudad principal— que era «capaz de resistir el clima de esas regiones», ${ }^{11}$ una admisión tácita de que el ejército peruano era tan «intruso» en el Amazonas como lo era su contraparte colombiana. Eventualmente, para el disgusto de aquellos que habían peleado en la batalla, la posición fue evacuada poco después, como resultado de negociaciones diplomáticas entre Lima y Bogotá.

Once años después, Lima tendría que despachar sus fuerzas militares para enfrentar otro desafío en la región del Amazonas, esta vez en la forma de una rebelión a lo largo del Departamento de Loreto. En vez de ser una rebelión de «salvajes», esta revuelta fue llevada a cabo por pobladores peruanos que habían migrado a Iquitos y se beneficiaban del próspero comercio de caucho, liderados por el capitán del ejército Guillermo Cervantes, que había participado en un golpe de estado en Lima en 1914 y en la batalla de La Pedrera. ${ }^{12}$ Similar a la rebelión de 1896, durante la cual el cuzqueño Mariano José Madueño había intentado establecer un régimen federal en el Departamento de Loreto, el objetivo de Cervantes era establecer una relación federal entre Iquitos y Lima (Basadre, 1961; Barclay, 2009; Torres Videla, [1922]). ${ }^{13} \mathrm{Y}$ como fue con el caso de la rebelión de Madueño, las élites letradas en Lima vieron en la rebelión de 1922 la amenaza de un intento secesionista oculta detrás de la retórica del federalismo, al punto que aun los políticos federalistas de otras regiones centrales se encolumnaron tras de Lima. Estas élites pueden haber recordado el caso de Acre, un territorio selvático que se rebeló contra el gobierno boliviano y acabó secesionándose y siendo anexado por Brasil en 1903 (García-Calderón, [1907] 2001). Las élites en Lima entonces consideraban que estas rebeliones no eran solo políticas, sino también amenazas directas a la integridad del geocuerpo reivindicado bajo la retórica del destino heredado. Una interpretación disidente era sostenida por el crítico literario y lealista de Leguía, Clemente Palma, quien repetidamente se burlaba de Cervantes y descartaba su rebelión como insignificante, afirmando que esta solo llevaría a su eventual exilio en Europa. ${ }^{14}$

11 El Comercio, 28 de agosto de 1911

12 Variedades, 24 de septiembre de 1921.

13 Véase West Coast Leader, 13 de agosto de 1921.

${ }^{14} V$ ariedades, 10 de septiembre, 29 de octubre, 5 de noviembre de 1921; 7 de enero de 1922. 
Destinos heredados: discursos de pérdida territorial en Estados poscoloniales a través del Pacífico (Perú y las Filipinas, 1903-1927)

JORGE BAYONA

A pesar de haber sido acusados de secesionistas, los rebeldes federalistas en Iquitos en realidad esgrimían la retórica del destino heredado como una de las causas principales de su revuelta. Entre las varias causas políticas de la revuelta desarrolladas en su manifiesto, se acusaba al gobierno de Leguía de «tratar de vender una de las regiones más ricas del territorio nacional: el Putumayo peruano, que el régimen, en su insaciable sed de oro, ¡ha ofrecido a Colombia a cambio de siete millones de soles!» (Torres Videla, [1922], p. 194). En un libro publicado en Brasil luego del colapso de la rebelión federalista, el secretario de Cervantes, Samuel Torres Videla, menciona todos los aspectos relacionados con este discurso, haciendo referencia a la naturaleza heredada de los reclamos de Perú, la amenaza de los «salvajes», la vasta riqueza natural que todavía espera ser extraída, y la necesidad de aumentar la presencia militar peruana para «civilizan» el territorio y expulsar a los intrusos colombianos. Acusa al presidente Leguía de haber estado dispuesto a vender los derechos del país en el Putumayo, especialmente luego de haber «cedido» territorio a Colombia después de la victoria de Perú en el conflicto de La Pedrera durante su primera presidencia (1908-1912), y en su lugar elogia a Julio C. Arana (el barón del caucho cuya compañía se involucró en la esclavización, asesinato y violación de las poblaciones indígenas del Putumayo) como un patriota verdadero que defendería los reclamos del Perú (pp. 88, 90). El hecho de que Arana haya nacido en San Martín, ubicado en la selva alta junto al «Perú metropolitano», y no en la selva baja, ejemplifica cómo aquellos que pelearon por mantener la región del Putumayo dentro de Perú no eran habitantes nativos, sino colonizadores recientes que esperaban preservar su acceso a los recursos. Y los elogios de Torres Videla a Arana muestran que por más severas que fueran las críticas a Leguía por sus tendencias autoritarias y reformas inconstitucionales, el foco general en la soberanía supera cualquier preocupación por el bienestar de los habitantes nativos.

El gobierno central en Lima procedió a reprimir la revuelta con fuerzas militares al enviar tropas que tuvieron que soportar la tortuosa marcha a Iquitos, ${ }^{15}$ así como barcos de guerra que navegaron pasando por el Estrecho de Magallanes y el río Amazonas a través de Brasil. El West Coast Leader describió el conflicto como «una guerrilla limitada por algunos meses a lo largo de los bancos de ríos de la jungla remota en un territorio completamente deshabitado», ${ }^{16}$ lo que subraya la débil posesión que del Estado peruano y «el pueblo peruano» tenía sobre ese territorio. Como resultado de reveses militares y bloqueos económicos, la rebelión colapsó luego de algunos meses.

Eventualmente, a pesar de la represión exitosa de la revuelta federalista, circunstancias tales como las pretensiones ecuatorianas y brasileñas sobre la

15 Variedades, 29 de abril 1922.

${ }^{16}$ West Coast Leader, 22 de enero de 1922. 
Destinos heredados: discursos de pérdida territorial en Estados poscoloniales a través del Pacífico (Perú y las Filipinas, 1903-1927)

JORGE BAYONA

región, así como las limitaciones logísticas que impedían una solución militar total a las «invasiones» colombianas, llevaron al gobierno de Leguía a considerar una solución diplomática a la disputa sobre la frontera. En 1922, Perú y Colombia negociaron un tratado en el que reconocían al río Putumayo como la frontera, y a un corredor que aseguraba el acceso al río Amazonas para Colombia. Los contenidos de este tratado no fueron revelados al público sino hasta 1927, confirmando de esta manera las sospechas que llevaron a la revuelta de 1921, y desencadenando una reacción adversa contra el gobierno. Estudiantes universitarios y organizaciones basadas en Iquitos lideradas por el infame Julio C. Arana expresaron su oposición a esta «cesión territorial». La oposición al tratado de 1922 también existía en las más altas esferas de la propia política limeña. El candidato presidencial y exmiembro del gabinete Germán Leguía criticó severamente el tratado firmado por su primo, el presidente Augusto Leguía: «Declaro desde ahora traidores a la Patria a quienes, con su voto, sancionaren aquel pacto inicuo; y me comprometo a descargar sobre ellos la sanción condigna de su crimen de lesa nacionalidad» (Basadre 1961, pp. 4068, 4036). Especialmente luego del escándalo del Putumayo, en el que la mejor defensa que podía hacer el gobierno peruano de cara a las atrocidades que habían tenido lugar en «su» territorio era argüir su falta de control sobre la región, el uso de una retórica tan vehemente parece fuera de lugar. La retórica del destino heredado, sin embargo, no era impermeable. Clemente Palma (1935) ofreció una mirada disidente al describir con desdén la posición legalista de los oponentes al tratado como un «empecinamiento patriotero de atenerse a la herencia colonial vaciada en papelotes virtualmente caducos de autoridad». Como seguidor del racismo leboniano, se vio compelido, sin embargo, a añadir sarcásticamente que consultar a los «salvajes nómades y a los loros y monos de la selva» en un plebiscito habría sido una "farsa grotesca», de esa manera permaneciendo dentro de los límites de una de las premisas fundamentales de la retórica del destino heredado (pp. 18, 22).

Al final, toda la oposición política al tratado no logró anularlo, y la frontera permaneció como fue establecida por el gobierno de Leguía. En 1932, luego de que Leguía fuera derrocado por el Teniente Coronel Luis Sánchez Cerro, un grupo de civiles peruanos invadió la ciudad de Leticia - ahora colombiana-, desencadenando una breve guerra internacional. Luego del asesinato de Sánchez Cerro en 1933, su sucesor, Óscar Benavides —el mismo oficial que había expulsado a los colombianos de La Pedrera veintidós años antes- se mostró reacio a alargar una guerra de grandes proporciones y procedió a poner fin al conflicto retornando a las fronteras establecidas en 1927. Después de todo, las medidas del ejército peruano habían asegurado la mitad del territorio del Putumayo reclamado por Perú, pero ya que la opinión política, no había logrado prevenir un «desmembramiento» del geocuerpo peruano, el tratado de 1927 
Destinos heredados: discursos de pérdida territorial en Estados poscoloniales a través del Pacífico (Perú y las Filipinas, 1903-1927)

JORGE BAYONA

perdura como una pérdida neta en la memoria peruana. Para una oposición más exitosa y no militar al desmembramiento territorial que toma como base la retórica del destino heredado, nos trasladamos ahora al caso de las Filipinas.

\section{Las Filipinas: sosteniendo la retórica del destino heredado bajo un nuevo amo colonial}

Las demandas de Manila por la totalidad de los reclamos territoriales españoles en el archipiélago fueron más directas y complicadas que las de Perú. La ausencia de una larga frontera terrestre — a pesar de lo poco explorado que estuvieracon otros imperios en la región evitó complicaciones similares a las enfrentadas por las repúblicas hispanoparlantes con Brasil, y la falta de múltiples estados sucesores al régimen imperial previno el problema de reclamos superpuestos sobre los remanentes territoriales de su predecesor. Ello hizo que fuera relativamente simple imaginar el archipiélago como el geocuerpo heredado. Los reclamos territoriales filipinos serían, sin embargo, complicados por la presencia de Estados musulmanes con los que los españoles habían firmado tratados, reconociendo de esa manera su autonomía -y, hasta cierto punto, su soberanía-, algo que nunca habían hecho con los habitantes de la Amazonia o los pueblos lumad que también vivían en el sur de las Filipinas.

Aunque la idea de qué territorios componían las Filipinas ya había existido por varios siglos, la base legal más reciente que marcó la totalidad del territorio reclamado por España en el Sudeste asiático fue el Tratado de París de 1898, por el cual el archipiélago fue cedido a los Estados Unidos a cambio de veinte millones de dólares. Este es el geocuerpo que los nacionalistas filipinos demandarían que se les transmitiera en su totalidad como su legítima herencia. ${ }^{17}$ En medio de los rumores de un posible desmembramiento de parte de la isla meridional de Mindanao del resto de las Filipinas, el político nacionalista Camilo Osías, por ejemplo, hizo un alegato que tomaba varios aspectos de la retórica del destino heredado: «Recibimos este país como un legado de nuestros antepasados. Debe ser nuestro propósito principal mantener y preservarlo como uno, compacto y unido, bajo la inspiración de un pasado histórico y un destino común, y transmitirlo de generación en generación en toda su integridad» (Quezón y Osías 1924, p. 191, énfasis añadido). ${ }^{18}$

Similar a lo que sucedía en Perú, esta herencia estaba fuertemente influenciada por las jerarquías sociales coloniales. A pesar de la ausencia de una clase criolla significativa, como aquellas de varias partes de América Latina, la legitimidad territorial española en las Filipinas tampoco reflejó la totalidad de las

17 El Mercantil en Manila Times, 17 de junio de 1926.

18 Véase también el editorial de 1906 en La Vida Filipina, como aparece en Gowing (1977, p. 205). 
Destinos heredados: discursos de pérdida territorial en Estados poscoloniales a través del Pacífico (Perú y las Filipinas, 1903-1927)

JORGE BAYONA

poblaciones nativas del archipiélago, y fue más bien asumido por los mestizos españoles o chinos más hispanizados que actuaban como una clase media en período colonial tardío, principalmente en las regiones tagaloparlantes. A diferencia de Tailandia —y más como Perú-, los reclamos de los pueblos tagalos sobre los territorios habitados por otros pueblos, en este caso los moros y los lumad, no estaban basados en una reinterpretación moderna de las relaciones tributarias entre varios Estados nativos, sino que más bien surgieron a partir de los reclamos que venían de la Manila española.

El componente «destino» de esta retórica está también, como en Perú, fuertemente influenciado por los recursos naturales que se creía que estaban esperando ser explotados en Mindanao y el archipiélago Sulu. En Mindanao, los estadounidenses en Davao visualizaban un próspero futuro en el abacá y el cáñamo - usado como fibra para usos textos textiles e industriales - y soñaban con extensos ranchos ganaderos en el centro de la isla, en la meseta Bukidnon, que se veía viable gracias al auge de la refrigeración y el transporte por barcos de vapor. Los intelectuales filipinos también eran conscientes de las riquezas posibles que esperaban ser descubiertas y explotadas, y estaban determinados a no perder el territorio. La retórica del destino heredado tiende a combinar las nociones jurídicas de herencia con los intereses concretos de la riqueza material, incitando de esta manera ávidos intereses «nacionales» en su futuro (Abinales, 2000; Edgerton, 2008). ${ }^{19}$

A pesar de las demandas filipinas por su «integridad territorial», podemos ver cómo la contradicción entre «ya poseídos» y «aún no conquistados» se manifestó en el archipiélago tanto como lo hizo en Perú. Hasta la década de 1840, las Filipinas españolas tenían que asumir una posición defensiva frente a las constantes expediciones marítimas en busca de esclavos de los moros que asaltaban sus costas, siendo generalmente incapaces de tomar represalias contra los navíos de facto extranjeros (Majul, 1973; Warren, 2007), y fue solo con la introducción de los cañoneros a vapor que España pudo alcanzar éxitos - muy limitados - contra los Estados moros del sur. Y como fue señalado anteriormente, en la práctica el control español sobre el lejano sur estaba limitado al área inmediata alrededor de sus guarniciones, que frecuentemente se encontraban a la defensiva, en vez de irradiar el poder español (Ileto, 1971; Warren, 2007). Cuánto esto era meramente una ocupación más que una anexión efectiva está demostrado por cuán fácilmente estos territorios volvieron a control moro una vez que la Revolución Filipina se desató en 1896. De esta manera, hacia el final del siglo XIX había un claro clivaje entre las Filipinas que

${ }^{19}$ Véase también Manila Times, 28 de abril, 3 de junio, 27 de junio, 16 de julio, 21 de agosto, 31 de diciembre de 1903; 4 y 8 de February de 1904; 16 de septiembre de 1910; 9, 11, 14 de junio de 1921; La Democracia,2 y 7 de septiembre de 1910. 
Destinos heredados: discursos de pérdida territorial en Estados poscoloniales a través del Pacífico (Perú y las Filipinas, 1903-1927)

$$
\text { JORGE BAYONA }
$$

efectivamente estaban controladas por los españoles y aquellas que solo podían reclamar en los mapas.

Este clivaje era experimentado por uno y otro lado de la grieta. En Manila, los artículos periodísticos frecuentemente resaltaban estas diferencias. El Renacimiento escribió que «varios filipinos que vivían cerca de Malabang han sido horriblemente mutilados en su misma casa por una partida armada de moros». ${ }^{20}$ Al oponer «filipino» — y no, digamos, bisayo o luzonero- a «moro», los filipinos letrados sugerían que estos últimos no pertenecían verdaderamente a la comunidad «filipina» más amplia, de esa manera considerándolos una suerte de presencia extranjera. El político y científico demócrata León María Guerrero, al argüir que los «filipinos» no albergaban el «barbarismo oriental», declaró que esto solo podía ser encontrado entre los moros y los lumad, que constituyen «excrecencias inútiles... llamadas a desaparecer de un organismo [filipino]». ${ }^{21}$ Por su parte, hay numerosos testimonios de moros separándose de los «filipinos», con la lamentación atribuida al sultán de Sulu siendo tal vez la más aguda: «iLas Filipinas!», exclamó el sultán impacientemente. «No soy parte de las Filipinas ni mi gente es filipina. He derrotado a los filipinos en la guerra, una y otra vez. No somos parte de las Filipinas como para ceder». ${ }^{22}$ Y aunque Oona Paredes (2013) ha identificado numerosos artefactos culturales entre los lumad que prueban que han sido más influenciados por el colonialismo español temprano de lo que se pensaba, su investigación etnográfica confirma que todo esto ya era una tradición olvidada hacia el siglo XX. Finalmente, Michael Hawkins (2013) ha demostrado que, para disgusto de las élites filipinas, varios oficiales militares estadounidenses invirtieron los factores de la ecuación a la vez que reconocían las diferencias entre los «filipinos» y los moros. La ferocidad, independencia y maneras «primitivas» de estos últimos los hacían superiores a los «filipinos», que eran vistos como indolentes, corruptos y tímidos como resultado del colonialismo español (pp. 26-53). ${ }^{23}$

\section{1. Reaccionando a las amenazas externas en Sulu-Mindanao}

\footnotetext{
${ }^{20}$ El Renacimiento, 24 de mayo de 1904, énfasis añadido. Para más ejemplos, véase también el 31 de diciembre de 1903; 5 de marzo, 14 de abril de 1904; Manila Times, 5 de septiembre de 1903.

${ }^{21}$ El Renacimiento, 17 de junio de 1904.

${ }^{2}$ Manila Times, 29 de julio de 1904, énfasis añadido. Para un ejemplo de un reconocimiento estadounidense al coraje moro, véase Manila Times, 8 de mayo de 1903.

${ }^{23}$ Para un ejemplo de reconocimiento americano al coraje Moro, ver Manila Times, 8 de mayo, 1904.
} 
Destinos heredados: discursos de pérdida territorial en Estados poscoloniales a través del Pacífico (Perú y las Filipinas, 1903-1927)

JORGE BAYONA

A pesar de estos claros cismas separando a los «filipinos» de los moros y los lumad, cuando la administración colonial estadounidense creó la Provincia Mora, de gestión militar y solo responsable ante el gobernador general y no ante la Asamblea Filipina, las élites filipinas vieron esto como una amenaza a su geocuerpo. Sospechaban de los motivos de los administradores estadounidenses, especialmente una vez que quedó claro que sus fuerzas armadas estaban asentándose para una permanencia larga en el área, contrastando con lo que se suponía, sería una administración significativamente más breve en el resto del país (Salamanca, 1968; Abinales, 2000). Las tensiones fueron exacerbadas cuando los empresarios estadounidenses basados en Mindanao también solicitaron a sus autoridades la separación permanente de Sulu-Mindanao o su anexión como un territorio no organizado de los Estados Unidos, y apoyaron una sugerencia en 1909 del Coronel Ralph Hoyt, gobernador a cargo de la Provincia Mora, y un proyecto de ley por el Representante Roger Bacon en 1926 (Gowing, 1977; Fry, 1978). ${ }^{24}$ Sin embargo, a diferencia de Perú, que pudo movilizar sus fuerzas armadas para luchar contra las «invasiones» colombianas, recurrir a la fuerza no era una opción en las Filipinas. En su lugar, la elite filipina se volcó al discurso público y a la prensa.

El primer curso de acción era atribuir motivaciones innobles a las intenciones estadounidenses de desmembrar a Sulu-Mindanao del resto del archipiélago. Lejos de cualquier interés altruista en «proteger a los moros de los filipinos», acusaron a los estadounidenses de estar interesados solamente en los vastos recursos naturales del territorio - aunque sus propios intereses en dichos recursos nunca fue un secreto-. Entre los casos más famosos de esta táctica estuvo el del periodista y nacionalista filipino Fidel Reyes, en cuyo editorial "Aves de Rapiña" en El Renacimiento en 1908 acusó al importante oficial estadounidense Dean Worcester de solo explorar los recursos de Mindanao y otras partes del archipiélago «para poseer todo la información y la llave a la riqueza nacional esencialmente para su beneficio personal». ${ }^{25} \mathrm{La}$ consecuente demanda por difamación de Worcester llevaría a la quiebra a El Renacimiento.

El otro abordaje fue, al menos nominalmente, limar asperezas con sus «paisanos» moros al enfatizar la armonía y las buenas relaciones entre cristianos y musulmanes para deslegitimar la pretensión estadounidense de estar protegiendo a los musulmanes de la hegemonía y la opresión católica. Ante todo, hubo un cambio en la nomenclatura: la dicotomía entre «filipinos» $\mathrm{y}$ «moros» (o

\footnotetext{
${ }^{24}$ El Renacimiento. 17 de agosto de 1905; Manila Times, 13 de junio de 1926

25 «Birds of Prey», como aparece en el Manila Times, 15 de enero de 1910. Véase también La Democracia, 2 de septiembre de 1910; El Debate en Manila Times, 1 de febrero de 1924; Philippines Herald en Manila Times, 14, 15, 18, 21 de junio de 1926; La Opinión en Manila Times, 14 de junio de 1926; Tribune en Manila Times, 22 de junio de 1926.
} 
Destinos heredados: discursos de pérdida territorial en Estados poscoloniales a través del Pacífico (Perú y las Filipinas, 1903-1927)

JORGE BAYONA

"moritos") de los primeros años del siglo XX se había convertido en una entre filipinos cristianos y filipinos moros hacia $1910 .{ }^{26} \mathrm{El}$ uso abundante de hermanos y compatriotas se convirtió en el estándar en la prensa filipina en un intento de crear una retórica de unidad de cara a las ambiciones territoriales de Estados Unidos. ${ }^{27}$ Si había conflicto entre los cristianos y los moros, era atribuido a la manipulación estadounidense, como fue el caso en 1926 de una caricatura en el Independent, en el que un personaje vestido elegantemente llamado «Imperialismo» intenta hacer que dos gallos llamados «Moro»y «Cristiano» se peleen entre sí (McCoy and Roces 1985, p. 142). ${ }^{28}$

El clímax vino cuando, en junio de 1926, llegaron noticias a Manila de un proyecto de ley del Representante Robert Bacon proponiendo la separación de Sulu-Mindanao —más la isla de Palawan_ del resto de las Filipinas, y la concesión de su propio gobierno autónomo. Howard Fry (1978) ha demostrado cómo son las motivaciones económicas las que yacen detrás del deseo de Bacon de separar las regiones meridionales: esta ley permitiría a los capitalistas estadounidenses esquivar las regulaciones establecidas por la Asamblea Filipina, que limitaban la concentración de la propiedad de la tierra, permitiéndoles labrar grandes plantaciones de caucho. Al presentar este proyecto, sin embargo, Bacon recurrió al viejo tropo de «proteger a los moros de los cristianos». Las noticias de la legislación propuesta provocaron una resistencia inmediata y enérgica de los políticos y periodistas filipinos, resultando en una reunión en la Gran Ópera de Manila, donde los filipinos «de todos los ámbitos de la vida» denunciaron esta amenaza a su geocuerpo. Todos los temas de conversación de la retórica del destino heredado fueron tocados en editoriales en periódicos y en discursos: la preservación de la integridad territorial de las tierras heredadas del período colonial, la riqueza natural del área amenazada y el rechazo a los alegatos sobre una enemistad entre cristianos y moros. ${ }^{29}$ Esto no evitó que el Tribune delineara un plan más concreto para defender los reclamos territoriales de Manila en el sur: «la necesidad inmediata es la conquista económica de la isla por los filipinos cristianos. Esta conquista, si fuera alcanzada, sería principalmente una cuestión

${ }^{26}$ La Democracia, 2 de septiembre de 1910.

27 Véase La Vanguardia en Manila Times, 19 de agosto de 1921; Philippines Herald en Manila Times, 30 de enero de 1924; El Debate en Manila Times, 1 de febrero de 1924; La Defensa en Manila Times, 18 de febrero de 1924; El Comercio en Manila Times, 19 de febrero de 1924; Philippines Herald en Manila Times, 25 de febrero de 1924. También Misión Parlamentaria Filipina (1923, p. 125).

${ }^{28}$ Véase también el editorial de 1910 en La Vanguardia en Gowing (1977, p. 253).

${ }^{29} \mathrm{El}$ periódico dirigido por estadounidenses Manila Times publicó una serie de editoriales de otros periódicos filipinos. Véase Manila Times, del 13 al 30 de junio de 1926. 
Destinos heredados: discursos de pérdida territorial en Estados poscoloniales a través del Pacífico (Perú y las Filipinas, 1903-1927)

JORGE BAYONA

de asentamiento. Hay que traer miles de filipinos a Mindanao». ${ }^{30}$ Aunque las circunstancias históricas les previnieron de llamar a medidas militares, la conquista demográfica a través de inmigración mientras se estuviera bajo la ocupación de Estados Unidos todavía era una opción.

La prensa estadounidense en Manila desestimó las protestas filipinas como prematuras y exageradas, y señaló - como lo había hecho en años anterioresque estaban empapadas en hipocresía, debido a que mientras reclamaban autodeterminación para sí mismos, se la denegaban a los moros. ${ }^{31} \mathrm{El}$ impulso por el proyecto claudicó de cara a la determinación de la oposición filipina, ya que no fue considerada para la sesión legislativa inmediata y perdió el apoyo local en Estados Unidos con la muerte del gobernador antifilipinización Leonard Wood. Una vez que la Gran Depresión golpeó a los Estados Unidos unos años después, el interés económico que el capitalismo estadounidense podría haber tenido en explotar Mindanao fue superado por la creencia de que estaba en el mejor interés del país abandonar las Filipinas tan pronto como fuera posible (Fry, 1978).

\section{2. Lidiando con amenazas desde dentro de Sulu-Mindanao}

Las amenazas al geocuerpo filipino vinieron no solo de los estadounidenses, sino también de las propias élites moras, que, con el apoyo y simpatía de los actores estadounidenses, solicitaron al gobierno de los Estados Unidos la separación permanente del futuro Estado filipino. En 1910, datus musulmanes manifestaron su oposición pública a ser puestos bajo autoridad filipina en una reunión en Zamboanga con el secretario de guerra Jacob M. Dickinson, demandando autonomía respecto a Manila; en 1913, otra reunión del estilo se llevó a cabo con el gobernador general Forbes. En 1921, otra solicitud en la que los moros pedían la separación de las Filipinas y su anexión a los Estados Unidos como un territorio fue presentado a la misión de Wood y Forbes. Finalmente, en 1924, una delegación de moros visitó al gobernador general Wood y una vez más pidieron la continuación del dominio estadounidense y la separación del resto del archipiélago (Gowing, 1977). ${ }^{32}$

Hay razones para sospechar que, si no fuera por la presencia imperial de Estados Unidos en el archipiélago, estos desafíos habrían llevado a Manila a enviar sus fuerzas armadas para reprimir el «separatismo» moro. En 1905, cuando un grupo de congresistas estadounidenses le preguntaron al abogado

\footnotetext{
30 Tribune en Manila Times, 18 de junio de 1926.

31 Manila Times, 20, 23 y 31 de agosto de 1921; 3 de febrero y 28 de junio de 1924; 18 y 28 de junio de 1926.

32 Véase también Manila Times, 24 de agosto de 1910; 17 de agosto de 1921; 10 de febrero de 1924.
} 
Destinos heredados: discursos de pérdida territorial en Estados poscoloniales a través del Pacífico (Perú y las Filipinas, 1903-1927)

JORGE BAYONA

batangueño Vicente Ilustre si los bisayos, moros y bicolanos se hubieran unido voluntariamente a los tagalos en una nueva república, contestó que creía que lo harían, pero si no lo hicieran, los recién formados ejército y armada filipinos los forzarían. $^{33}$ En 1924, el semanario nacionalista Independent declaró que el problema moro podría ser resuelto con «unos pocos batallones de guardias rurales» y publicó una caricatura en la que un personaje filipino observa al Tío Sam estrangulando a un «indio rojo» estereotipado y luego comenta: «debería hacer lo mismo con los moros» (McCoy and Roces, 1985, p. 182).

La presencia imperial estadounidense, por supuesto, impedía la opción militar. Cuando se alegó que la Policía filipina había asesinado a un número de líderes musulmanes que se habían quejado ante la misión Wood-Forbes, las autoridades estadounidenses rápidamente investigaron la situación y dejaron en claro que no tolerarían esas actividades de parte de los filipinos cristianos. ${ }^{34}$ De esta manera, la única herramienta que le quedaba a las élites de Manila para contrarrestar el separatismo de las comunidades musulmanas era volcarse a los periódicos y la opinión pública. Uno de sus cursos de acción era cuestionar la validez y legitimidad de las quejas que los líderes musulmanes expresaban contra el dominio filipino. Por ejemplo, La Democracia acusó al líder moro Hadji Buto de ser «un empleado del gobierno y de los espléndidamente pagados y prudentemente tolerados», sugiriendo que sus quejas estaban motivadas por razones estadounidenses, no moras. ${ }^{35} \mathrm{Y}$ aun cuando los llamamientos por el separatismo eran domésticos, eran representadas como egoístas y antiprogresistas, como era el caso de La Vanguardia, donde la resistencia a la integración era descrita como motivada por deseos de mantener privilegios entre la élite mora como la poligamia y la esclavitud (Gowing, 1977). Era, por supuesto, el llamado de los filipinos metropolitanos a emancipar a los musulmanes comunes de la tiranía de sus sultanes y datus. ${ }^{36}$

En este sentido, una táctica complementaria era, como se señaló anteriormente, enfatizar los puntos en común entre los «filipinos cristianos»y los «filipinos no cristianos». A este respecto, los filipinos fueron mucho más veloces que los peruanos en argüir que aquellos a quienes antes habían representado como «salvajes» eran en realidad miembros —aunque jóvenesde la nación. Tan temprano como 1905, el periódico nacionalista El Renacimiento

\footnotetext{
33 Manila Times, 29 de agosto de 1905.

34 Manila Times, 18 y del 21 al 22 de agosto de 1921.

35 La Democracia, 30 de agosto de 1910.

${ }^{36}$ Véanse los editoriales de El Debate y El Ideal en Manila Times, 22 de agosto de 1921; el editorial de El Debate en Manila Times, 30 de agosto de 1921; el editorial de El Debate en Manila Times, 13 de febrero de 1924; el editorial de La Defensa en Manila Times, 18 de febrero de 1924; y la editorial de La Opinión en Manila Times, 30 de junio de 1926.
} 
Destinos heredados: discursos de pérdida territorial en Estados poscoloniales a través del Pacífico (Perú y las Filipinas, 1903-1927)

JORGE BAYONA

declaró que «no es el deseo de predominancia, sino la integridad de un país poblado por miembros de una sola raza que nos compele a encender las alarmas», ${ }^{37}$ algo que por supuesto se encuentra en contradicción directa con otros artículos en los que marcaban una clara distinción entre «moritos» y filipinos. ${ }^{38}$ También es verdad, como ha sido señalado por James Warren (2007), que desde que los asaltantes moros se casaban frecuentemente con las filipinas que secuestraban de Luzón y las Visayas, había cierta verdad en la pretensión filipina de que compartían sangre con los musulmanes del sur. De todos modos, los filipinos afirmaban que luego de ganar cierto grado de autoridad sobre los moros y los lumad con la eliminación de la Provincia Mora en 1920, un gran progreso se había alcanzado en el proceso de «civilizarlos», al punto de que «los habitantes no cristianos han mostrado su justa apreciación de los beneficios que sus hermanos cristianos han compartido con ellos. El sentimiento nacional en esa parte de las Filipinas es casi tan fuerte como en las provincias cristianas» (Misión Parlamentaria Filipina 1923, p. 125). Los filipinos hicieron una transición hacia nociones de gubernamentalidad respecto a sus poblaciones no convencionales mucho más rápido de lo que lo hicieron los peruanos.

Es difícil discernir hasta qué grado los moros verdaderamente creían en esta retórica de hermandad con los filipinos metropolitanos. Sobre el curso de la mayor parte de este período, los filipinos de elite basados en Manila hablaban sobre la voluntad de los moros sin haber sido capaces de presentar un solo moro que adhiriera a esa posición. No fue sino hasta 1924 que líderes moros que apoyaran la unidad con Luzón y las Visayas pudieron ser producidos por la prensa filipina, escribiendo que los musulmanes, igorrotes, negritos e ilongotes prominentes declaraban que «suscriben a nuestros ideales proindependentistas y que son leales a nuestros líderes nacionales respecto a las cuestiones políticas trascendentales en nuestra vida nacional». ${ }^{39}$ De todos modos, las relaciones entre Manila y las poblaciones musulmanas de Sulu-Mindanao continuaron siendo tensas en las décadas siguientes. Aunque Joy Sales (2013) ha hallado que una nueva generación de líderes musulmanes en los años treinta abogaron por una causa común con los cristianos en buscar la independencia de los Estados Unidos, R. J. May (1992) ha identificado por lo menos un momento más en el que los líderes moros solicitaron separarse del resto de las Filipinas en 1935. La agitación continua en Mindanao en el presente es un síntoma de cómo los clivajes entre las comunidades cristianas y las musulmanas y lumad, aún no han sido completamente resueltos.

${ }^{37}$ El Renacimiento, 18 de agosto de 1905. Véase Quezón y Osías (1924, pp. 9-12).

${ }^{38}$ El Renacimiento, 24 de mayo, 29 de agosto, 14 y 15 de noviembre de 1904.

${ }^{39}$ Philippines Herald en Manila Times, 25 de febrero de 1924. Véase también Manila

Times, 2 de marzo de 1924 
Destinos heredados: discursos de pérdida territorial en Estados poscoloniales a través del Pacífico (Perú y las Filipinas, 1903-1927)

JORGE BAYONA

\section{Conclusiones}

Aunque los flujos y reflujos de la economía capitalista global jugaron un papel importante en las luchas por el control sobre la región del Putumayo y SuluMindanao, no debemos pasar por alto las fuerzas culturales incrustadas en la retórica del destino heredado. Una vez que el geocuerpo objetivo fue conceptualizado alrededor del momento de la separación del Imperio Español, las élites en Lima y Manila se esmeraron en hacerlo realidad y, con los medios que tenían a mano - la fuerza militar en el caso de Perú y el discurso público en el caso de las Filipinas - se opusieron a cualquier intento de desmembrar su «integridad territorial». Al hacerlo, se involucraron en una lógica de soberanía legal sobre el territorio y recurrieron a argumentos legalistas, mientras que al mismo tiempo mostraron una actitud contradictoria hacia los territorios: eran «simultáneamente ya poseídos»y «aún no conquistados». Y mientras las élites peruanas permanecieron completamente inconscientes del bienestar de los pueblos indígenas que vivían en los territorios disputados, sus contrapartes filipinas fueron más veloces en moverse hacia un modelo de gubernamentalidad, enfocándose en el «mejoramiento» de las sus poblaciones, y en considerarlos connacionales. Tomaría varias décadas más hasta que los peruanos adoptaran este sistema. Es completamente posible, sin embargo, que esto estuviera condicionado por la necesidad de los filipinos de «probarse a sí mismos» como administradores capaces de continuar con el sistema a través del cual los estadounidenses justificaban ante sí mismos su presencia continuada en el archipiélago. Uno podría especular que, si las Filipinas hubieran conservado su independencia, la región tagala podría haber procedido a comportarse en una manera similar de cara a las regiones mora y lumad a cómo lo hizo Lima respecto a la región de la Amazonia.

De todos modos, el estudio del discurso del destino heredado en casos como los de Perú y de las Filipinas nos permite observar a través de la retórica y conceptualizar los esfuerzos peruanos y filipinos en estas regiones como parte de un proyecto continuado de imperialismo heredado de sus antecesores españoles. De esta manera, podemos ver más allá de los sistemas nacionalista y de «construcción nacional», y estudiarlos como parte de una historia más amplia del imperialismo y del colonialismo de poblamiento en los siglos XIX y XX. Observar a Lima y Manila como metrópolis imperiales por derecho propio, y sus territorios en el este y sur como posesiones coloniales, probará ser académicamente productivo.

\section{Referencias bibliográficas}

ABINALES, P. (2000). Making Mindanao: Cotabato and Davao in the Formation of the Philippine Nation-State. Quezon City: Ateneo de Manila University Press. 
Destinos heredados: discursos de pérdida territorial en Estados poscoloniales a través del Pacífico (Perú y las Filipinas, 1903-1927)

JORGE BAYONA

Anderson, B. (1998). The Spectre of Comparisons: Nationalism, South-east Asia, and the World. London: Verso.

Anderson, B. (2006). Imagined Communities: Reflections on the Origin and Spread of Nationalism. Rev. ed. London: Verso.

Anderson, B. (2016). A Life beyond Boundaries. London: Verso.

BARCLAY, F. (2009). El estado federal de Loreto, 1896: centralismo, descentralización y federalismo en el Perú a fines del siglo XIX. Lima: IFEA- CERA Bartolomé de las Casas.

BASAdre, J. (1961). Historia de la República del Perú. Lima: Ediciones Historia.

BELAUNDE, V.A. (1930) 1963. La realidad nacional. Lima: Talleres Gráficos P. L. Villanueva.

Belaunde, V. A. (1942). La vida internacional del Perú. Lima: Imprenta Torres Aguirre. Blanco, John D. 2004. "Bastards of the Unfinished Revolution: Bolivar's Ismael and Rizal's Martí at the Turn of the Twentieth Century." Radical History Review 89, no. 1: 92-114.

Chakrabarty, D. (2000). Provincializing Europe: Postcolonial Thought and Historical Difference. Princeton, N.J.: Princeton University Press.

Cueto, M. (2001). The Return of Epidemics: Health and Society in Peru during the Twentieth Century. Aldershot, U.K.: Ashgate.

Edgerton, R.B. (2008). People of the Middle Ground: A Century of Conflict and Accommodation in Central Mindanao, 1880s-1980s. Quezon City: Ateneo de Manila University Press.

Foucault, M. (2007). Security, Territory, Population: Lectures at the Collège de France, 1977-1978. New York: Basingstoke.

FRY, H.T. (1978). "The Bacon Bill of 1926: New Light on an Exercise in Divideand-Rule." Philippine Studies 26, no. 3: 257-73.

García-CALdERón, F. (1907) 2001. El Perú contemporáneo. Lima: Fondo Editorial del Congreso del Perú.

GARCía JordÁN, P. (2001). Cruzy arado, fusiles y discursos: La construcción de los orientes en el Perú y Bolivia, 1820-1940. Lima: Instituto Francés de Estudios Andinos.

Gowing, P. (1977). Mandate in Moroland: The American Government of Muslim Filipinos, 1899-1920. Quezon City: University of the Philip- pines System.

HAWKINS, M. (2013). Making Moros: Imperial Historicism and American Military Rule in the Philippines' Muslim South. DeKalb, Ill.: NIU Press. Hollnsteiner, Mary Racelis, and Judy Celine Ick. 2001. Bearers of Benevo- lence: The Thomasites and Public Education in the Philippines. Pasig City: Anvil.

IlETO, R. (1971). Magindanao, 1860-1888: The Career of Dato Uto of Buayan. Ithaca, N.Y.: Southeast Asia Program, Cornell University.

Loos, T. (2006). Subject Siam: Family, Law, and Colonial Modernity in Thailand. Ithaca, N.Y.: Cornell University Press. 
Destinos heredados: discursos de pérdida territorial en Estados poscoloniales a través del Pacífico (Perú y las Filipinas, 1903-1927)

JORGE BAYONA

Majul, C. (1973). Muslims in the Philippines. Quezon City: University of the Philippines Press.

Mallon, F. (1995). Peasant and Nation: The Making of Postcolonial Mexico and Peru. Berkeley: University of California Press.

MARIÁtegui, J. C. (1928) 1943. Siete ensayos de interpretación de la realidad peruana. Lima: Biblioteca "Amauta."

MARIÁtegui, J. C. (1969). Ideología y política. Lima: Biblioteca "Amauta.”

MAY, R. J. (1992). "The Wild West in the South: A Recent Political History of Mindanao." In Mindanao: Land of Unfulfilled Promise, edited by Mark Turner, R. J. May, and Lulu Respall, 125-46. Quezon City: New Day. McCoy, Alfred, and Alfredo Roces. 1985. Philippine Cartoons: Political Caricature of the American Era, 1900-1941. Quezon City: Vera-Reyes.

Mignolo, W. (2003). The Darker Side of the Renaissance: Literacy, Territoriality, and Colonization. Ann Arbor: University of Michigan Press. Misión Parlamentaria Filipina. 1923. Nuestra demanda de libertad. Manila: Bureau of Printing.

PALma, C. (1935). Habia una vez un hombre: artículos políticos. Lima: Partido Democrático Reformista.

PAredes, O. (2013). A Mountain of Difference: The Lumad in Early Colonial Mindanao. Ithaca: Southeast Asia Program, Cornell University.

Pons Muzzo, G. (1962). Las fronteras del Perú: historia de los límites. Lima: Ediciones del Colegio San Julián.

Quezón, M. L. \& OsíAs, C. (1924). Governor-General Wood and the Filipino Cause. Manila: Manila Book Company.

SalamancA, B. (1968). The Filipino Reaction to American Rule, 1901- 1913. Hamden, U.K.: Shoe String Press.

SALES, J. (2013). "AA Common Fate': The Role of Muslim Leaders in the Philippine Independence Movement, 1935-1941." The Mellon Mays Undergraduate Fellowship Journal 7: 98-101.

SOMmer, D., ed. (1999). The Places of History: Regionalism Revisited in Latin America. Durham, N.C.: Duke University Press.

STANFIELD, M. (1998). Red Rubber, Bleeding Trees: Violence, Slavery, and Empire in Northwest Amazonia, 1850-1933. Albuquerque: University of New Mexico Press.

Strate, S. (2015). The Lost Territories: Thailand's History of National Humiliation. Honolulu: University of Hawai'i Press.

TORRES VidelA, S. (1922). La revolución de Iquitos (Loreto-Perú). Pará: Tip. España. Warren, James. 2007. The Sulu Zone, 1768-1898: The Dynamics of External Trade, Slavery and Ethnicity in the Transformation of a Southeast Asian Maritime State. Singapore: National University of Singapore Press.

Winichakul, T. (1994). Siam Mapped: A History of the Geo-body of a Nation. Honolulu: University of Hawai'i Press. 

